\title{
BMJ Open Vertebroplasty in patients with multiple myeloma with vertebral compression fractures: protocol for a single-blind randomised controlled trial
}

Line Adsboell Wickstroem (D) , ${ }^{1}$ Leah Carreon, ${ }^{1}$ Thomas Lund, ${ }^{2}$ Niels Abildgaard, ${ }^{2}$ Marianne Dyrby Lorenzen, ${ }^{1}$ Mikkel Østerheden Andersen ${ }^{1}$

To cite: Wickstroem LA, Carreon L, Lund T, et al. Vertebroplasty in patients with multiple myeloma with vertebral compression fractures: protocol for a single-blind randomised controlled trial. BMJ Open 2021;11:e045854. doi:10.1136/ bmjopen-2020-045854

- Prepublication history for this paper is available online. To view these files, please visit the journal online (http://dx.doi. org/10.1136/bmjopen-2020045854).

Received 23 0ctober 2020 Accepted 02 August 2021

Check for updates

(C) Author(s) (or their employer(s)) 2021. Re-use permitted under CC BY-NC. No commercial re-use. See rights and permissions. Published by BMJ.

${ }^{1}$ Center for Spine Surgery and Research, Sygehus Lillebalt Middelfart Sygehus, Middelfart, Denmark

${ }^{2}$ Department of Haematology, Odense University Hospital, Odense, Denmark

Correspondence to

Dr Line Adsboell Wickstroem; line.adsboll.wickstrom@rsyd.dk

\section{ABSTRACT}

Introduction Multiple myeloma (MM) is a plasma cell cancer where about $1 / 3$ of the patients present with pathological fractures at the time of diagnosis. Despite treatment, the majority of the patients will develop additional fractures. Because survival and prognosis has improved significantly over the last two decades for patients with $\mathrm{MM}$, there is an increased need to focus on optimal fracture treatment. Traditionally, fracture pain is treated conservatively with opioids, bisphosphonates, bracing and radiation therapy. Vertebral augmentation has been used for the last three decades as a minimally invasive treatment option for vertebral compression fractures, but the evidence base for the efficacy is weak. We describe a trial assessing the impact of vertebroplasty on clinical outcome in the treatment of patients with MM with painful vertebral fractures. Methods 100 patients with MM with painful vertebral fractures will be randomised in a prospective, singleblinded, multicentre, clinical trial where patients are randomised to either usual care or usual care supplemented with vertebroplasty with a possibility of crossover 4 weeks after randomisation. The primary outcome will be change in 0swestry Disability Index at 4 weeks.

Analysis Primary and secondary outcomes are assessed at baseline and at 4, 8, 26 and 52 weeks. Categorical data will be presented by means of frequencies and related percentages; continuous data will be displayed by means of descriptive statistics.

Ethics and dissemination The study has been evaluated by the Regional Committees on Health Research for Southern Denmark (S-20200075) and notified and approved by the Region of Southern Denmark and listed in the internal record, journal no. 20/22355. All participants provide consent. The protocol will follow the SPIRIT (Standard Protocol Items for Randomized Trials) statement. The Danish Myeloma Patient Organization supports the study. Findings will be disseminated in peer-reviewed publications and presented at national and international conferences.

Trial registration number NCT04533217.

\section{INTRODUCTION}

Multiple myeloma (MM) is a plasma cell cancer in the bone marrow associated with
Strengths and limitations of this study

- Randomised controlled trial.

- Nationwide study (participation of all haematological departments in Denmark).

Single-blinded randomisation.

activated osteoclastic bone degradation, lack of bone formation and pathological fractures with protracted healing due to inhibited osteoblast function. ${ }^{2}$ These biological changes are induced by the expansion of proliferating malignant plasma cells in the bone marrow. $^{2}$

The incidence is about 7 per 100.000 in Denmark, equivalent to approximately about 400 new cases a year. ${ }^{3}$ At the time of diagnosis, pathological fractures are present in about $1 / 3$ of the patients and a greater proportion develop fractures during the course of the disease. $^{34}$ The annual risk of spontaneous spinal fractures is $15 \%-24 \%$ despite bisphosphonate prophylaxis. ${ }^{3}$

Although MM is incurable, survival and prognosis has improved significantly over the last two decades. ${ }^{5}$ This justifies and necessitates increased focus on optimal fracture treatment to ensure good physical function and quality of life for the patients' remaining lifetime. Vertebral fractures are very painful and affect patients' daily function. ${ }^{2}{ }^{46}$ Traditionally, the fracture pain is treated conservatively with opioids, bisphosphonates, bracing and radiation therapy. ${ }^{3}$

Vertebroplasty was first reported in the late 1980 s for the treatment of vertebral haemangiomas and osteolytic vertebral tumours. ${ }^{7}$ Under fluoroscopy, a Jamshidi needle is inserted through the pedicles ${ }^{8}$ into the vertebral body. Polymethylmethacrylate (PMMA) is injected into the vertebral body, still under 
imaging guidance, to minimise extravasation into the spinal canal. Vertebral augmentation, including percutaneous vertebroplasty (PVP) and kyphoplasty (KP), has been used as a minimally invasive treatment option for vertebral compression fractures (VCFs). ${ }^{4910}$

The procedure is considered to be well suited for treatment of patients with malignant spine disease as it can be done under local anaesthesia, provides rapid pain relief $^{11} 12$ and prevents prolonged immobilisation. PVP and KP provide stability within the fractured vertebral body by preventing microscopic movement and macroscopic collapse. It has also been suggested that PMMA bone cement induces exothermic reactions that are toxic to nerve endings and therefore provide pain relief. ${ }^{13}$

Two randomised trials and a later review was published in $2009^{14}{ }^{15}$ and $2018,{ }^{16}$ respectively, regarding vertebral augmentation. The two trials were done in different patient populations, namely patients with benign osteoporosis. The disappointing outcome of these two trials has unfortunately led to uncertainties regarding the effect in other indications, such as metastatic disease.

In 2019, a systematic review on vertebral augmentation of cancer-related painful vertebral lesions was published. ${ }^{12}$ This review included randomised studies and other publications involving vertebral augmentation techniques. In all, 87 studies were included in the study and metaanalysis was performed. The review demonstrated clinically relevant improvement in pain and health-related quality of life (HRQL).

A recent Danish national clinical guideline ${ }^{17} 18$ on painful VCFs, caused by cancer including MM, recommends PVP as pain management. The evidence is mainly based on two randomised studies: the Cancer Patient Fracture Evaluation (CAFE) study by Berenson et al $^{19}$ including 49 patients suffering from MM randomised between KP and conservative treatment and the study by Audat $e t a l^{20}$ randomising 27 patients to either conventional therapy or conventional therapy adding vertebroplasty or KP. The recommendations in the Danish guideline are weak due to risk of bias, including lack of blinding in randomised studies. In addition, the CAFE study was further downgraded for indirectness as the study contains a population consisting predominantly of patients with primary cancer other than MM.

\section{Rationale for this study}

Evidence-based guidelines for supplementing chemotherapy with vertebral augmentation when treating patients with MM with pathological fractures are lacking. The overall evidence from the two randomised controlled trials comparing supplementary vertebral augmentation to usual care is of low quality ${ }^{1718}$ and requires more robust investigations regarding the role of vertebroplasty in the treatment algorithm of MM with spinal involvement.

For that reason, we decided to perform a single-blinded, randomised, controlled trial comparing usual care versus usual care supplemented with vertebroplasty in treating patients with MM with pathological fractures.
METHODS AND ANALYSIS

\section{Purpose}

To examine the efficacy of PVP in patients with MM with VCF, based on improvement in patient-reported outcome.

\section{Patient and public involvement}

The initial idea behind this project was created by a patient appointed by the Danish Cancer Society to participate in the working group behind the National Clinical Guideline on PVP for the palliative treatment of malignant VCFs caused by MM. ${ }^{17}{ }^{18}$ She urged the group members to set up a study to provide high-quality evidence needed to recommend the treatment.

The study design has been developed in collaboration with the Danish Myeloma Patients' Association 'Dansk Myelomatose Forening'.

\section{Study design}

The study design is a randomised, prospective, singleblinded, multicentre, clinical trial where patients are randomised to either usual care or usual care supplemented with vertebroplasty with a possibility of crossover 4 weeks after randomisation. It is designed in accordance with the SPIRIT (Standard Protocol Items: Recommendations for Interventional Trials) guidelines. ${ }^{21}$

\section{Trial sites}

The trial is a multicentre trial with the participation of all Danish haematological departments. The departments are as follows:

- Department of Haematology, Aalborg University Hospital.

- Department of Haematology, Aarhus University Hospital.

- Department of Haematology, Holstebro Regional Hospital.

- Department of Haematology, University Hospital of Southern Denmark, Esbjerg.

- Department of Haematology, University Hospital of Southern Denmark, Vejle.

- Department of Haematology, Zealand University Hospital, Roskilde.

- Department of Haematology, Herlev Hospital.

- Department of Haematology, Rigshospitalet, Copenhagen.

- Department of Haematology, Odense University Hospital.

Participating spine surgical units are as follows:

- Department of Orthopaedic Surgery, Rigshospitalet.

- Spine Center of Southern Denmark, Lillebaelt Hospital, Middelfart.

- Department of Orthopaedic Surgery, Aarhus University Hospital.

\section{Study population}

Study subjects will be recruited from patients diagnosed with MM assessed and found eligible for vertebroplasty due to painful VCFs. Possible candidates will be identified at the 
departments of haematology where the patients are treated for their disease.

\section{Inclusion criteria}

- Patients diagnosed with symptomatic MM and spinal compression fractures.

- Fractures verified on MRI- or CT-scan (OF-type 1-4) between and including Th6 and L5.

- Fracture involves four vertebral body levels or less.

- PVP can be done in one session.

- Possible indication for vertebroplasty.

- Back pain score measured on a visual analogue scale (VAS) $\geq 5$.

- Age $\geq 18$ years.

- Able to understand and read Danish.

- Written informed consent.

- Relevant pain started $\leq 3$ months prior to inclusion.

\section{Exclusion criteria}

- Contraindications for spine surgery:

- Platelets $<30 \mathrm{mia} / \mathrm{L}$.

- OF-type 5 and Pincer-type.

- Bedridden.

- Presence of neurological deficit.

- Psychological or psychiatric disorder that is expected to interfere with compliance.

\section{Randomisation}

Prior to randomisation, the patients will be divided into two groups, stratifying between patients with known MM with a newly diagnosed spinal fracture and relevant pain $\leq 3$ months prior to inclusion and patients with newly diagnosed MM with relevant pain associated to a spine fracture initiating $\leq 3$ months prior to the diagnosis.

Furthermore, to ensure balanced control and intervention groups, the included patients at randomisation will be stratified according to (1) planned PVP of 1 vs 2-4 levels and (2) former vertebral fractures that are not planned treated with PVP.

The patients in each subgroup will be randomised to one of two parallel treatment arms allocated in a 1:1 ratio. Sealed numbered envelopes containing electronically randomised group allocations will be prepared prior to trial commencement. Following informed consent, a sealed prerandomised envelope will be allocated by the study nurse and the patient label affixed to the envelope.

\section{Control treatment}

The patients will receive the treating departments' standard care, following the Danish National Guidelines. ${ }^{22}$

\section{Investigational treatment}

The investigational treatment arm will be the group receiving supplementary vertebroplasty of the VCFs.

\section{Outcomes}

Primary outcome

- Back-specific Functional Status using Oswestry Disability Index (ODI) at time of randomisation and 4 weeks postrandomisation. The ODI assesses pain-related physical functioning in spinal disorders. ${ }^{23}$ The ODI contains 10 questions about how back pain affects the ability to manage everyday life. These are summarised in a score ranging from 0 to 100 . Higher scores reflect worse pain and disability.

\section{Secondary outcomes}

- Self-reported average pain intensity (VAS) during the preceding 24 hours at enrolment, and weekly in 12 weeks after enrolment. The rating scale from 0 to 10 , with higher scores indicating more severe pain.

- HRQL on the EuroQol 5-dimension 3-level (EQ-5D-3L). ${ }^{24}$ EQ-5D-3L is a widely used generic measure of HRQL. It evaluates five dimensions: mobility, self-care, usual activities, pain/discomfort and anxiety/depression, each with three levels of severity. The resulting health is converted into a single summary index with a total score ranging from -0.6 to 1 , where 1 corresponds to perfect health.

- HRQL according to the EORTC (European Organisation or Research and Treatment of Cancer) quality of life questionairres EORTC QLQ C30 and EORTC MY20.

- Long-term stability of the treated vertebral bone (eg, fracture, including refracture, vertebral body height or malalignment) as measures by long-standing radiographs.

- Questionnaire about general health services, including questions about for example, sick leave and home care.

\section{Data collection}

After informed consent is obtained from the patient, the haematologist will fill out screening forms regarding disease stage, lines of treatment, current disease status, bisphosphonate status and pain relief treatment. The patient will complete surveys including the ODI, VAS pain score and QoL. Time points for data collection are presented in table 1 .

\section{Sample size}

The sample size calculations for this study is a challenge, as there are very few published papers reporting outcomes following vertebroplasty on vertebral fractures due to MM. The sample size calculations are thus based on results from treating osteoporotic vertebral fractures with vertebroplasty. To obtain a minimal clinically relevant improvement of at least 15 points on the ODI, we need to enrol 44 patients in each group. To account for approximately $10 \%$ dropout, we aim to enrol 100 patients.

$$
\left.\mathrm{N}=(\mathrm{Z}(\text { crit })+\mathrm{Z}(\mathrm{pwr})) \mathrm{x} \mathrm{s}^{2} * 2 / \mathrm{MIREDIF}^{2}\right)
$$

with a mean minimum difference between groups of $15, \mathrm{SD}=25$, two-tailed $\mathrm{p}=0.05$, assuming a normal distribution with $\mathrm{Z}$ (crit) $=1.96, \mathrm{Z}$ (pwr) $=0.80$. 


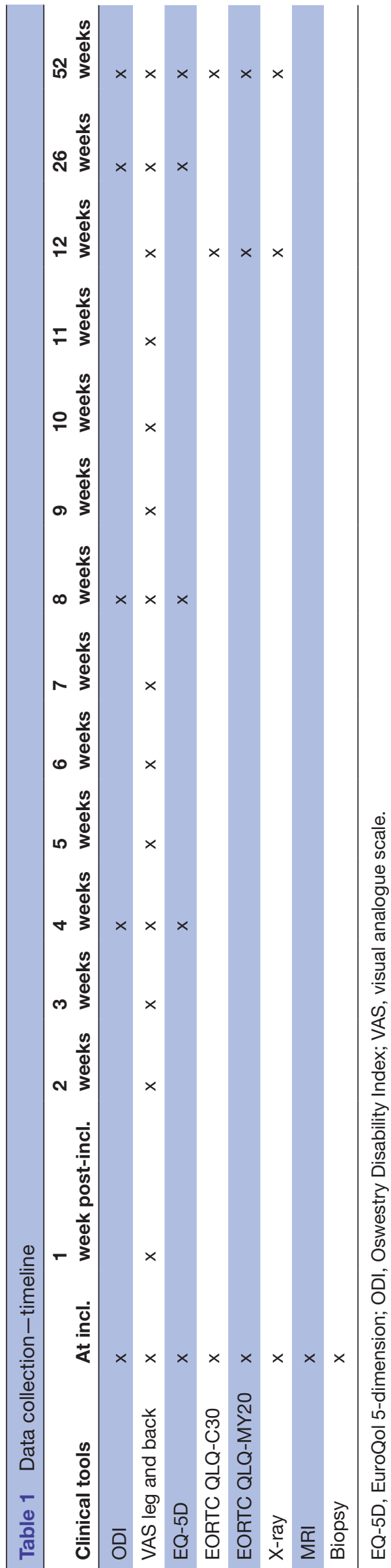

Analyses

Baseline characteristics

The baseline characteristics of patients and operative details including complications will be recorded.

\section{Statistical analysis}

Data will be analysed according to their type using STATA, that is, categorical data will be presented by means of frequencies and related percentages; continuous data will be displayed by means of descriptive statistics (mean, SD, number of observations, minimum, median, maximum).

The primary outcome measure will be improvement in ODI scores at 4 weeks after initiation of treatment. Repeated measures ANCOVA (Analysis of Covariance) with baseline ODI, VAS pain, EQ-5D-3L and number of levels involved will be performed.

\section{Ethics and dissemination}

The study will be performed according to the Declaration of Helsinki and the Danish Code of Conduct for Research Integrity. ${ }^{25}$ The study has been evaluated by the Regional Committees on Health Research for Southern Denmark (S-20200075) and has been notified to and approved by the Region of Southern Denmark and listed in the internal record, journal no. 20/22355, and permission to extract data from hospital records will be obtained from the patients. Consent to use patient-reported information from the DaneSpine database is obtained electronically prior to patients completing the questionnaires. Patients who do not consent will not be included.

Findings will be disseminated in peer-reviewed publications and presented at national and international conferences following guidance from the SPIRIT guidelines.

\section{DISCUSSION}

This article presents a protocol for a single-blinded randomised controlled trial comparing usual care versus usual care supplemented with vertebroplasty in treating patients with MM with painful vertebral fractures. Further prospectively registered data on health, social variables and patient-reported outcomes are collected.

As the median survival is significantly better for patients with MM than for patients with spinal metastases associated with solid cancers, it justifies and necessitates increased focus on optimal fracture treatment in patients with MM specifically. An increasing number of patients with MM experience more than 5 years, even more than 10 years survival, which highlights the importance of ensuring good physical function and quality of life for the patients.

The outcome of the proposed project will impact future national and international guidelines on the treatment regimen for patients with MM and vertebral fractures.

The main strength of this study is the randomised treatment assignments, reducing the risk of selection bias.

Contributors LAW: PhD student, investigator; LC: cosupervisor; TL: consultant, mediation of contact to the Danish Myeloma Patients' Association 'Dansk 
Myelomatose Forening'; NA: cosupervisor, mediation of contact to the Danish haematological departments; MDL: administration; MØA: principal supervisor. All authors have participated in the design and organisation of the study.

Funding Expenses, including salary, tuition fees and miscellaneous, are applied for from the following: Faculty of Health Sciences, University of Southern Denmark; Research means, Region of Southern Denmark or Hospital Lillebaelt Research Committee; External funding.

Competing interests None declared.

Patient and public involvement Patients and/or the public were involved in the design, or conduct, or reporting, or dissemination plans of this research. Refer to the Methods section for further details.

Patient consent for publication Not required.

Provenance and peer review Not commissioned; externally peer reviewed.

Open access This is an open access article distributed in accordance with the Creative Commons Attribution Non Commercial (CC BY-NC 4.0) license, which permits others to distribute, remix, adapt, build upon this work non-commercially, and license their derivative works on different terms, provided the original work is properly cited, appropriate credit is given, any changes made indicated, and the use is non-commercial. See: http://creativecommons.org/licenses/by-nc/4.0/.

ORCID iD

Line Adsboell Wickstroem http://orcid.org/0000-0003-3238-4259

\section{REFERENCES}

1 Bataille R. The multiple myeloma bone eco-system and its relation to oncogenesis. Morphologie 2015;99:31-7.

2 Thorsteinsdottir S, Gislason G, Aspelund T, et al. Fractures and survival in multiple myeloma: results from a population-based study. Haematologica 2020;105:1067-73.

3 Simony A, Hansen EJ, Gaurilcikas M, et al. Pain reduction after percutaneous vertebroplasty for myeloma-associated vertebral fractures. Dan Med J 2014;61:A4945.

4 Kyriakou C, Molloy S, Vrionis F, et al. The role of cement augmentation with percutaneous vertebroplasty and balloon kyphoplasty for the treatment of vertebral compression fractures in multiple myeloma: a consensus statement from the International myeloma Working Group (IMWG). Blood Cancer J 2019;9:27.

5 Gregersen H, Vangsted AJ, Abildgaard N, et al. The impact of comorbidity on mortality in multiple myeloma: a Danish nationwide population-based study. Cancer Med 2017;6:1807-16.

6 Hall SE, Criddle RA, Comito TL, et al. A case-control study of quality of life and functional impairment in women with long-standing vertebral osteoporotic fracture. Osteoporos Int 1999;9:508-15.

7 Galibert P, Deramond H, Rosat P, et al. [Preliminary note on the treatment of vertebral angioma by percutaneous acrylic vertebroplasty]. Neurochirurgie 1987;33:166-8.

8 Zoarski GH, Stallmeyer MJB, Obuchowski A. Percutaneous vertebroplasty: a to Z. Tech Vasc Interv Radiol 2002;5:223-38.

9 Malhotra K, Butler JS, Yu HM, et al. Spinal disease in myeloma: cohort analysis at a specialist spinal surgery centre indicates benefit of early surgical augmentation or bracing. BMC Cancer 2016;16:444.
10 Nas Ömer Fatih, İnecikli MF, Hacıkurt K, et al. Effectiveness of percutaneous vertebroplasty in patients with multiple myeloma having vertebral pain. Diagn Interv Radiol 2016;22:263-8.

11 Patel MS, Ghasem A, Greif DN, et al. Evaluating treatment strategies for spinal lesions in multiple myeloma: a review of the literature. Int $J$ Spine Surg 2018;12:571-81.

12 Sørensen ST, Kirkegaard AO, Carreon L, et al. Vertebroplasty or kyphoplasty as palliative treatment for cancer-related vertebral compression fractures: a systematic review. The Spine Journal 2019;19:1067-75.

13 Trumm CG, Jakobs TF, Zech CJ, et al. Ct fluoroscopy-guided percutaneous vertebroplasty for the treatment of osteolytic breast cancer metastases: results in 62 sessions with 86 vertebrae treated. $J$ Vasc Interv Radiol 2008;19:1596-606.

14 Buchbinder R, Osborne RH, Ebeling PR, et al. A randomized trial of vertebroplasty for painful osteoporotic vertebral fractures. $N$ Engl J Med 2009;361:557-68.

15 Kallmes DF, Comstock BA, Heagerty PJ, et al. A randomized trial of vertebroplasty for osteoporotic spinal fractures. $N$ Engl J Med 2009;361:569-79.

16 Buchbinder R, Johnston RV, Rischin KJ, et al. Percutaneous vertebroplasty for osteoporotic vertebral compression fracture. Cochrane Database Syst Rev 2018;4:CD006349.

17 Danish Society of Spinal Surgery, 2020. Danish national guideline on treatment of multiple myeloma patients with vertebroplastyDanish Society of Spinal Surgery. Available: http://drks.ortopaedi.dk/ wp-content/uploads/2020/02/NKR-for-perkutan-vertebroplastik-tilpalliativ-behandling-af-maligne-sammenfald-i-ryggen.pdf [Accessed 27 Aug 2021].

18 Rousing R, Kirkegaard AO, Nielsen M, et al. Percutaneous vertebroplasty as treatment of malignant vertebral lesions: a systematic review and grade evaluation resulting in a Danish national clinical guideline. Eur Spine J 2020;29:1573-9.

19 Berenson J, Pflugmacher R, Jarzem P, et al. Balloon kyphoplasty versus non-surgical fracture management for treatment of painful vertebral body compression fractures in patients with cancer: a multicentre, randomised controlled trial. Lancet Oncol 2011;12:225-35.

20 Audat ZA, Hajyousef MH, Fawareh MD, et al. Comparison if the addition of multilevel vertebral augmentation to conventional therapy will improve the outcome of patients with multiple myeloma. Scoliosis 2016:11:47.

21 Spirit. Standard protocol items: recommendations for interventional trials guidelineThe SPIRIT group. Available: https://www.spiritstatement.org/publications-downloads/ [Accessed 23 Mar 2020].

22 Danish health authority, 2016. Danish national guideline on treatment of multiple myelomaDanish Health Authority. Available: https://www. sst.dk/-/media/Udgivelser/2019/Pakkeforloeb-kraeft-2015-2019/ Myelomatose-2016/Pakkeforl\%C3\%B8b-for-myelomatose-\%E2\% 80\%93-revision-sep-2016 endelig.ashx?la=da\&hash=45E5D966 276C45B1DEC5B9D4749CE98E37B3EC0A [Accessed 11 Mar 2021]

23 Fairbank JC, Pynsent PB. The Oswestry disability index. Spine 2000;25:2940-53.

24 Obradovic M, Lal A, Liedgens $\mathrm{H}$. Validity and responsiveness of EuroQol-5 dimension (EQ-5D) versus short Form-6 dimension (SF-6D) questionnaire in chronic pain. Health Qual Life Outcomes 2013;11:110.

25 The Danish code of conduct for research integrity - UddannelsesOG Forskningsministeriet. Available: http://ufm.dk/publikationer/ 2014/the-danish-code-of-conduct-for-research-integrity 